\title{
PERANCANGAN SISTEM INFORMASI REKAMBT TRAINING CENTRE BERBASIS DEKSTOP(STUDI KASUS PADA HRD PT. BUMITANGERANG MESINDOTAMA)
}

\author{
Dedeh Supriyanti ${ }^{1}$ \\ Adi Kusuma Widya Tama ${ }^{2}$ \\ Ikhsan Bakhri ${ }^{3}$ \\ Dosen AMIK Raharja Informatika ${ }^{1,}$ Dosen STMIK Raharja ${ }^{2}$, STMIK Raharja Jurusan Teknik \\ Informatika $^{3}$ \\ Jl. Jendral Sudirman No. 40, Modernland, Kota Tangerang ${ }^{1,2,3}$ \\ E-mail: dedeh@raharja.info ${ }^{1}$, adi.kusuma@raharja.info ${ }^{2}$, ikhsan.bakhri@raharja.info ${ }^{3}$
}

\begin{abstract}
ABSTRAK
Perkembangan teknologi pada era modern seperti saat ini berpengaruh pada bidang teknologi informasi. Tidak terkecuali pada perusahaan yang sudah mulai memperbaharui sistem manual ke sistem yang sudah terkomputerisasi. Tingkat kecepatan serta ketepatan sangatlah penting dan menjadi nilai utama pada sebuah sistem, oleh karena itu sebuah sistem harus mendukung teknologi yang memadai. Demikian halnya yang terjadi pada PT. Bumitangerang Mesindotama yang sudah menerapkan sistem yang sebagian besar sudah terkomputerisasi. Seperti halnya departemen HRD pada PT. Bumitangerang Mesindotama yang sudah menerapkan sistem berbasis komputer namun belum maksimal dalam penggunaannya dan masih saja menggunakan cara manual menggunakan media kertas, hal ini pula yang memberatkan staff HRD di dalam penginputan data training karyawan yang berakibat tidak tercapainya prestasi kerja karyawan. Di dalam pembuatan sistem serta penelitian ini penulis menggunakan metode SWOT (strengths, weaknesses, opportunities, \& threats), serta juga menggunakan metode observasi, wawancara, dan studi pustaka. Perangkat lunak yang digunakan adalah bahasa pemrograman Basic dan aplikasi Visual Basic. Dengan program aplikasi BT Training Centre ini diharapkan bisa meminimalkan kesalahan penginputan data serta memudahkan dalam pencarian data karyawan yang sudah mengikuti pelatihan ataupun prestasi karyawan lainnya dan memudahkan untuk mengekspor data untuk keperluan lainnya.
\end{abstract}

Kata Kunci : Training, BT Training Centre, SWOT, Sistem

\begin{abstract}
The development of technology in today's modern era has an impact on the field of information technology. No exception for companies that have started to update the manual system to computerized system. The level of speed and accuracy is very important and the main value of a system, therefore the system must support adequate technology. Similarly, what happens to PT. Bumitangerang Mesindotama who has implemented a system that has been largely computerized. Like the HRD department at PT. Bumitangerang Mesindotama who has implemented the computer-based system but has not maximized its use and still using manual using paper media, it also burdens HRD staff in entering employee training data resulting in not achievement of employee work performance. In the making of this system and research, the author uses SWOT method (strengths, weaknesses, opportunities, \& threats), and also use the method of observation, interview, and literature study. The software used is a Basic programming language and Visual Basic application. With BT Training Center application program is expected to minimize data entry error and facilitate the search data of employees who have followed the training or training and facilities to export data for other purposes.
\end{abstract}

Keywords: Training, BT Training Center, SWOT, System 


\section{PENDAHULUAN}

Perkembangan teknologi informasi terus mengalami kemajuan yang sangat signifikan sesuai dengan kebutuhan masyarakat, instansi, maupun organisasi terkait. Dalam hal menghadapi persaingan yang begitu ketat, setiap organisasi maupun instansi akan memperioritaskan kemudahan dan kecepatan.

Di dunia ini banyak sekali ide-ide dan inovasi kreatif yang membuat manusia sangat terbantu di dalam segala bidang tak terkecuali dalam bidang teknologi informasi.

Kemajuan teknologi informasi tentu saja tidak bisa diserap dengan hanya mengandalkan perangkat-perangkat lawas dan masih berkutik dengan cara yang serba manual, maka dari itu teknologi komputerisasi sangatlah penting pada era teknologi seperti sekarang ini.

Media komputerisasi mejadi solusi terbaik dalam memperbaiki sistem yang belum sepenuhnya optimal.

Demikian halnya dengan PT. Bumitangerang Mesindotama Seiring dengan perkembangan jaman jumlah sumber daya manusia yang berkompeten dan berkualitas semakin dibutuhkan. Hal ini pula yang menyebabkan perusahaan harus menyediakan sebuah solusi untuk memperbaiki dan mengevaluasi kinerja dan prestasi karyawan.

Terkait hal tersebut, manajemen perusahaan harus semaksimal mungkin untuk memperdayakan sumber daya manusia yang telah dimiliki perusahaan untuk mencapai produktivitas dan kinerja yang lebih unggul.

Fenomena yang terjadi di PT. Bumitangerang Mesindotama adalah karyawan sangat sulit untuk mendapatkan pengakuan dikarenakan tidak adanya sistem rekam jejak untuk setiap karyawan dan hanya mengandalkan riwayat serta tatap muka saja sedangkan keahlian dan kemampuan tidak diikutsertakan.

Kesenjangan inipula yang mengakibatkan karyawan yang memiliki kualitas dan tidak akan sulit terekspos serta akan mengakibatkan turunnya kualitas karyawan dan ketidakadilan.

Tugas inilah yang menjadi tantangan seorang kepala HRD untuk merekap setiap data karyawan serta Training untuk memudahkan pencarian karyawan yang mempunyai bakat dan keahlian untuk disalurkan ke divisi yang membutuhkan.

Karna dari itu perusahaan harus menyediakan sarana yang menunjang karyawan dan membantu meningkatkan prestasi serta kinerja karyawan. Melalui media rekam jejak ini karyawan akan terpantau dan akan termotivasi untuk menjadi yang lebih baik lagi.

\section{KAJIAN PUSTAKA}

Menurut Dessler dalam Agusta dan Susanto (2013:1), mendefinisikan pelatihan sebagai berikut: Pelatihan adalah proses mengajarkan karyawan baru atau yang ada sekarang, keterampilan dasar yang mereka butuhkan untuk menjalankan pekerjaan mereka".

Tujuan umum dan tujuan khusus pelatihan menurut Sedarmayanti (2013:170)adalah sebagai berikut

a. Tujuan Umum Pelatihan

Tujuan umum pelatihan adalah meningkatkan produktivitas organisasi, dengan melalui berbagai kegiatan antara lain :

1. Mengembangkan pengetahuan sehinggga pekerjaan dapat diselesaikan secara rasional.

2. Mengembangkan keterampilan/keahlian, sehingga pekerjaan dapat diselesaikan lebih cepat dan efektif. 
3. Mengembangkan/merubah sikap, sehingga menimbulkan kemauan kerjasama dengan sesama karyawan dan manajemen (pimpinan).

a. Tujuan Khusus Pelatihan

1. Kualitas.

2. Produktivitas kerja.

3. Mutu perencanaan tenaga kerja.

4. Semangat/moral.

5. Balas jasa tidak langsung.

6. Kesehatan dan keselamatan kerja.

7. Cegah kadaluarsa pengetahuan dan keterampilan.

8. Pengembangan diri.

Rekam jejak (track record) adalah semua hal yang seseorang atau organisasi telah lakukan di masa lalu, yang menunjukkan seberapa baik mereka dalam melakukan pekerjaan, mengatasi masalah, dll ${ }^{[4]}$.

Adapun tujuan sistem menurut Azhar Susanto (2013: 23) dalam bukunya yang berjudul Sistem Informasi Akuntansi adalah sebagai berikut:

"Tujuan sistem merupakan target atau sasaran akhir yang ingin dicapai oleh suatu sistem. Agar supaya target tersebut bisa tercapai, maka target atau sasaran tersebut harus diketahui terlebih dahulu ciri-ciri atau kriterianya. Upaya mencapai suatu sasaran tanpa mengetahui ciri-ciri atau kriteria dari sasaran tersebut kemungkinan besar sasaran tersebut tidak akan pernah tercapai. Ciri-ciri atau kriteria dapat juga digunakan sebagai tolak ukur dalam menilai suatu keberhasilan suatu sistem dan menjadi dasar dilakukannya suatu pengendalian ".

Kualitas Informasi menurut Lippeveld, Sauborn, dan Bodart di dalam bukunya Bambang Hartono (2013:17-18):

1. Relevansi

Informasi disediakan atau disajikan untuk digunakan. Oleh karena itu, informasi yang bernilai tinggi adalah yang relevan dengan kebutuhan, yaitu untuk apa informasi itu akan digunakan

2. Kelengkapan dan Keluasan.

Informasi akan bernilai semakin tinggi, jika tersaji secara lengkap dalam cakupan yang luas. Informasi yang sepotong-sepotong, apalagi tidak tersusun sistematis, tentu tidak akan banyak artinya. Demikian pun bila informasi itu hanya mencangkup area yang sempit dari suatu permasalahan.

3. Kebenaran

Kebenaran informasi ditentukan oleh validitas atau dapatnya dibuktikan. Informmasi berasal dari data, dan data fakta. Informasi yang bernilai tinggi adalah informasi yang benar-benar berasal dari fakta, bukan opini atau ilusi.

4. Terukur

Informasi berasal dari data arau hasil pengukuran dan pencacatan terhadap fakta. Jadi, informasi yang bernilai tinggi adalah informasi yang jika dilacak kembali kepada datanya, data tersebut dapat diukur sesuai dengan faktanya.

5. Keakuratan

Informasi berasal dari data arau hasil pengukuran dan pencacatan terhadap fakta. Oleh karena itu kecermatan dalam mengukur dan mencatat fakta akan menentukan keakuratan data dan nilai dari informasi yang dihasilkan.

6. Kejelasan 
Informasi dapat disajikan dalam berbagai bentuk teks, tabel, grafik, chart, dan lainlain. Namun, apa pun bentuk yang dipilih, yang penting adalah menjadikan pemakai mudah memahami maknanya. Oleh sebab itu, selain bentuk penyajiannya harus benar, juga harus diperhatikan kemampuan pemakai dalam memahaminya.

7. Keluwesan

Informasi yang baik adalah yang mudah diubah-ubah bentuk penyajiannya sesuai dengan kebutuhan dan situasi yang dihadapi.

8. Ketepatan Waktu

Informasi yang baik adalah informasi yang disajikan tepat pada saat dibutuhkan. Informasi yang terlambat datang menjadi informasi basi yang tidak ada lagi nilainya (misalnya untuk pengambilan keputusan).

Di dalam sebuah komponen sistem informasi terdapat beberapa bagian yang saling berhunungan dan akan terbentuk sebuah sistem.

Menurut Al-Bahra (2013:14), Komponen Sistem Informasi terdapat 5 komponen dan dapat diklasifikasikan sebagai berikut:

1. "Hardware dan Software yang berfungsi sebagai mesin.

2. People dan procedures yang merupakan manusia dan tatacara menggunakan mesin.

3. Data merupakan jembatan penghubung antara manusia dan mesin agar terjadi suatu proses pengolahan data."

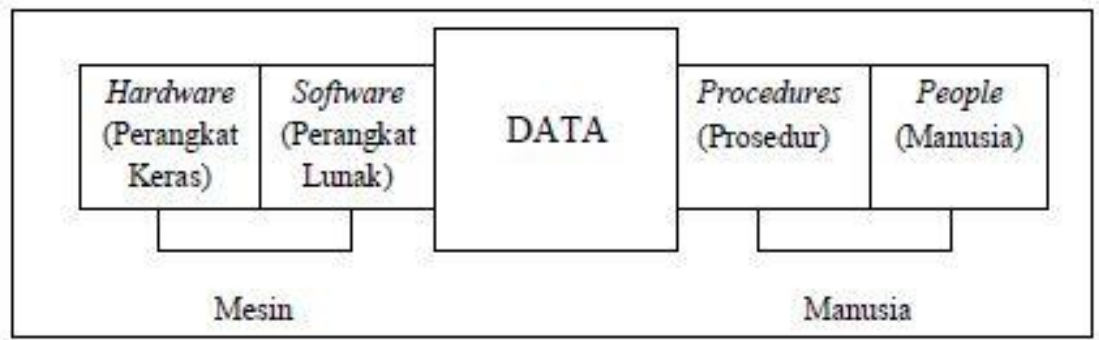

Gambar 1. Komponen Sistem Informasi

Sumber: Al-Bahra Bin Ladjamudin (2013:15)

\section{PERUMUSAN MASALAH}

Berdasarkan dengan latar belakang diatas maka permasalahan yang akan dibahas adalah:

1. Apa yang menjadi kendala atas kurangnya pengumpulan riwayat karyawan dan cara mengatasinya?

2. Apa yang menjadi belum tersedianya aplikasi untuk menunjang riwayat atau rekam jejak kinerja serta prestasi karyawan!

3. Bagaimana cara implementasi dan pengumpulan data karyawan yang sangat berguna untuk menunjang peringkat dan kualitas karyawan!

4. Bagaimana membuat informasi HRIS (Human Resource Information System) khususnya pada masalah Rekam Taining yang sistematis, terarah dan dapat meningkatkan kinerja yang lebih efisien dan cepat?

\section{KAJIAN LITERATURE}

1. Penelitian yang dilakukan oleh Ainnur Rofiq, Sholiq, dan Feby Artwodini Muqtadiroh, pada tahun 2013 yang berjudul "Rancang Bangun Aplikasi Sistem 
Informasi Manajemen Pelatihan (SIMPEL) pada Lembaga Pelatihan XYZ”. Pada penelitian ini menjelaskan kesulitan pihak lembaga pelatihan XYZ yang selalu menggunakan perangkat lunak Ms. Excel untuk mengelola data peserta pelatihan yang ada. Sedangkan untuk koordinasi antar cabang hanya dilakukan dengan menggunakan telepon atau email. Metode pengelolaan data seperti diatas kurang efektif dan efisien. Masalah pengorganisasian data peserta dan koordinasi antar cabang menjadi masalah utama yang dihadapi oleh lembaga pelatihan XYZ dalam mengadakan pelatihan. Masalah tersebut dapat diselesaikan dengan sebuah perangkat lunak sistem informasi manajemen berbasis web.

2. Penelitian yang dilakukan oleh Imanaji Hari Sayekti, pada tahun 2013 yang berjudul "Analisa Pengembangan Sistem Aplikasi E-Training Karyawan Berbasis WEB Pada PT.Mutiara Solusindo". Subjek penelitian ini adalah para karyawan dan aplikasi itu sendiri. Objek penelitian adalah aspek reliability, usability, maintainability, dan portability. Setting penelitian mengambil tempat di PT. Mutiara Solusindo dan perusahaan lain sebagai pengguna aplikasi. Metode yang digunakan dalam pengumpulan data adalah pengamatan langsung terhadap aplikasi e-training dan melakukan survei dengan menyebarkan angket kuisioner yang dibuat ke dalam sebuah program aplikasi. Adapun metode yang digunakan untuk analisis data antara lain pengujian keandalan, analisis data skala likert, dan analisis langsung terhadap baris kode serta analisis kemampuan aplikasi dijalankan pada lingkungan yang berbeda.

3. Penelitian yang dilakukan oleh Agung Tri Retnowati pada tahun 2017 yang berjudul "Aplikasi Pembekalan Karwayan Baru di Yomart Menggunakan Training Jarak Jauh". Pada penelitian ini menjelaskan tentang sistem informasi yang baik harus bisa menghasilkan informasi yang berkualitas yang berguna dalam pengambilan keputusan karena informasi tersebut harus bisa menjangkau kepentingan manajemen di berbagai tingkatan manajemen. Untuk itu perlu adanya suatu aplikasi yang dapat membantu perusahaan dalam memberikan pelatihan bagi karyawan barunya.

4. Penelitian yang dilakukan oleh Dian Octorasari, dan Weda Adistianaya Dewa pada tahun 2016 yang berjudul "Aplikasi Pelatihan Interaktif Pada PT. KSI (PT. Kosmetikatama Super Indah_Inez Kosmetik)". Permasalahan yang terjadi pada divisi Trainer adalah pelatihan kepada internal karyawan, yaitu Beauty Advisor (BA) dan Beauty Consultant (BC), yang harus di datangi langsung oleh Trainer ke masingmasing area marketing yang tersebar di seluruh Indonesia. Penelitian ini memberikan suatu solusi pada permasalahan yang terjadi dengan cara mengembangkan sekaligus mempublikasikan melalui media perancangan multimedia interaktif, menarik, mudah digunakan dan tepat sasaran.

\section{PEMBAHASAN}

\section{Metode Analisa Sistem}

a. Metode SWOT

Pada penelitian ini penulis akan melakukan analisa dengan menggunakan metode SWOT untuk mengevaluasi kekuatan (Strenght), kelemahan (Weakness), peluang (Opportunities), dan ancaman (Threat) sehingga sistem yang akan dibuat dibuat akan menjadi solusi dari pemecahan masalah yang ada saat ini. 
Tabel 1. Identifikasi Sistem Dengan Menggunakan Metode SWOT

\begin{tabular}{|c|c|c|}
\hline & Strenght & Weakness \\
\hline $\begin{array}{l}\text { Faktor } \\
\text { Internal }\end{array}$ & $\begin{array}{l}\text { 1. Sistem yang sudah digunakan } \\
\text { pada divisi atau departement } \\
\text { HRD sudah terkomputerisasi. }\end{array}$ & $\begin{array}{l}\text { 1. Sistem untuk melalakukan } \\
\text { rekam training sebagian } \\
\text { besar masih menggunakan } \\
\text { secara manualisasi. } \\
\text { 2. Sebagian besar banyak } \\
\text { rekam training karyawan } \\
\text { yang tidak terdeteksi }\end{array}$ \\
\hline & Opportunities & Threat \\
\hline $\begin{array}{c}\text { Faktor } \\
\text { Eksternal }\end{array}$ & $\begin{array}{l}\text { 1. Kebutuhan akan adanya } \\
\text { aplikasi rekam training } \\
\text { karyawan yang simpel. }\end{array}$ & $\begin{array}{l}\text { 1. Hilangnya data karyawan } \\
\text { training. } \\
\text { 2. Rumitnya mencari data } \\
\text { karyawan training. }\end{array}$ \\
\hline
\end{tabular}

Berdasarkan identifikasi dari tabel diatas dengan menggunaan metode SWOT, selanjutnya akan dilakukan analisa untuk mencari strategi dengan menggunakan matriks SWOT. Matrik SWOT adalah sebuah alat yang dapat menggambarkan tentang pencocokan yang penting bagaimana peluang yang tersedia untuk mengatasi suatu ancaman dengan menggembangkan empat jenis strategi S-O (Kekuatan-Peluang), strategi W-O (KelemahanPeluang), strategi S-T (Kekuatan-Ancaman), strategi W-T (Kelemahan-Ancaman).

Tabel 2. Matriks SWOT Sistem Rekam Training Kayawan

\begin{tabular}{|c|c|c|}
\hline I & Strenght & Weakness \\
\hline \multirow{2}{*}{ 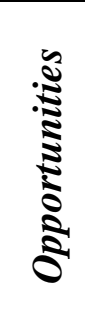 } & $\mathrm{SO}$ & WO \\
\hline & $\begin{array}{l}\text { Mengembangkan sebuah sistem rekam } \\
\text { karyawan training untuk mempermudah } \\
\text { pencarian riwayat karyawan yang teah } \\
\text { mengikuti training secara akurat. }\end{array}$ & $\begin{array}{l}\text { Menciptakan sebuah sistem HRIS } \\
\text { yang dapat menaungi semua berkas } \\
\text { yang bersifat terkomputerisasi. }\end{array}$ \\
\hline \multirow[b]{2}{*}{ 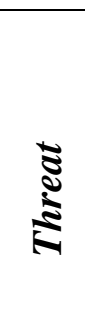 } & ST & WT \\
\hline & $\begin{array}{l}\text { Membuat sistem yang dapat mengimpor } \\
\text { serta mengekspor data berupa excel dan } \\
\text { pdf serta menghasilkan hasil yang lebih } \\
\text { akurat. }\end{array}$ & $\begin{array}{l}\text { Mengembangkan sebuah sistem } \\
\text { HRIS khususnya Rekam Training } \\
\text { yang dapat beroperasi dengan } \\
\text { mudah, cepat dan lebih efisien }\end{array}$ \\
\hline
\end{tabular}

\section{Analisa Masukan, Analisa Proses, Analisa Keluaran}

a. Analisa Masukan

Nama Dokumen : Employee Training Evaluation

Fungsi Dokumen : Untuk Mengetahui Nilai Evalusai Training Karyawan 
Sumber Dokumen : Bagian HRD

Tujuan Dokumen : Manajer HRD

Media : Kertas

Jumlah : Tergantung Banyaknya Peserta Training (Pelatihan)

Bentuk : DOC FM-G, 1.2-000 (Tergantung Departement)

b. Analisa Proses

Nama Modul : Permintaan Input Dokumen

Masukan : Employee Training Evaluation

Keluaran : Evaluasi Jenjang Karir Per Departemen

Ringkasan Proses : Staff HRD melakukan pelatihan terhadap karyawan di berbagai departemen sehingga menghasilkan nilai dari per pelatihan lalu staff HRD memberikan nilai evaluasi ke Manajer HRD untuk disetujui sebagai syarat untuk jenjang karir karyawan.

c. Analisa Keluaran

Nama Dokumen : Dievaluasi dan Diketahui Oleh Departemen dan Manajer HRD Fungsi Dokumen : Untuk dikembalikan ke staff HRD serta untuk merekam riwayat pelatihan per karyawan sebagai syarat penunjang jenjang karir.

Sumber Asal Dokumen : Employee Training Evaluation

Media : Kertas dan Komputer

\section{Konfigurasi Sistem Yang Berjalan}

a. Spesifikasi Perangkat Keras (Hardware)

1. Processor : Intel(R) Core(TM) i3-3220 CPU @ 3.30GHz (4 CPUs)

2. Motherboard: Gigabyte Technology Co., Ltd.

3. Monitor : Samsung LCD S19C150F

4. Mouse : USB Logitech B100

5. Keyboard : USB Logitech K120

6. RAM : $2 \mathrm{~GB}$

7. Harddisk : $500 \mathrm{~GB}$

8. Printer : Epson L360

b. Spesifikasi Perangkat Lunak (Software)

1. Microsoft Windows XP Professional/7 Ultimate

2. Microsoft Office 2007

c. Hak Akses (Brainware)

Untuk mengoperasikan atau mengolah data yang diperlukan hanya dapat diakses oleh staff HRD.

\section{Perancangan Sistem}

Perancangan ini menjelaskan tentang bagaimana alur penginputan data karyawan training dengan lebih mudah dan simple daripada sistem sebelumnya. 


\section{Use Case Diagram}

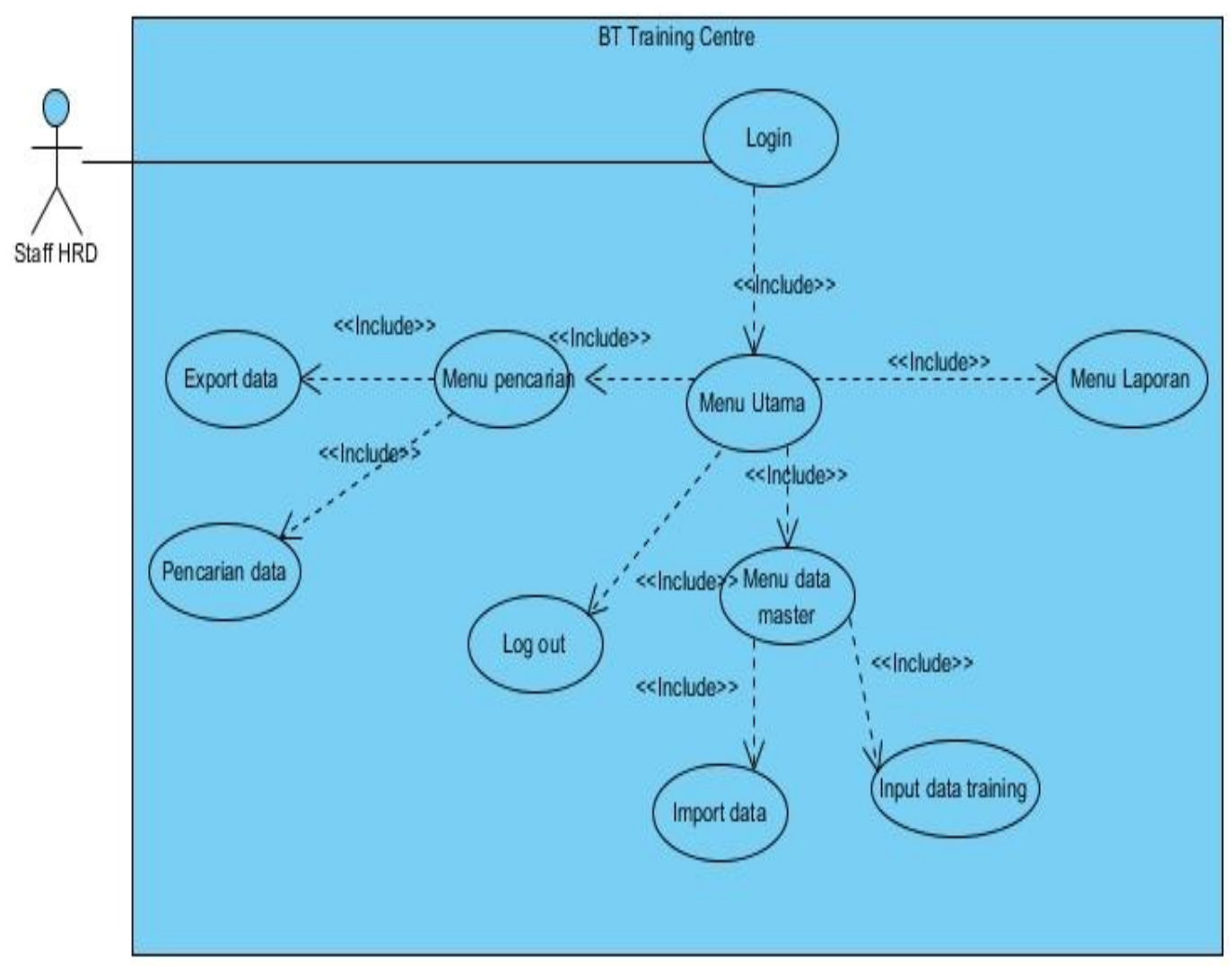

Gambar 2. Use Case Diagram Rekam BT Training Centre

Pada Use Case Diagram diatas dapat dideskripsikan sebagai berikut:

1. User merupakan aktor

2. User membuka sistem, melakukan login dan membuka menu utama

3. User melihat menu data master, menu pencarian, menu laporan dan menu log out.

4. User melakukan input dan imput pada menu data master

5. User melakukan export data excel dan pencarian data dalam menu pencarian

6. User dapat mencetak laporan dalam menu laporan

7. User dapat logout 


\section{Activity Diagram}

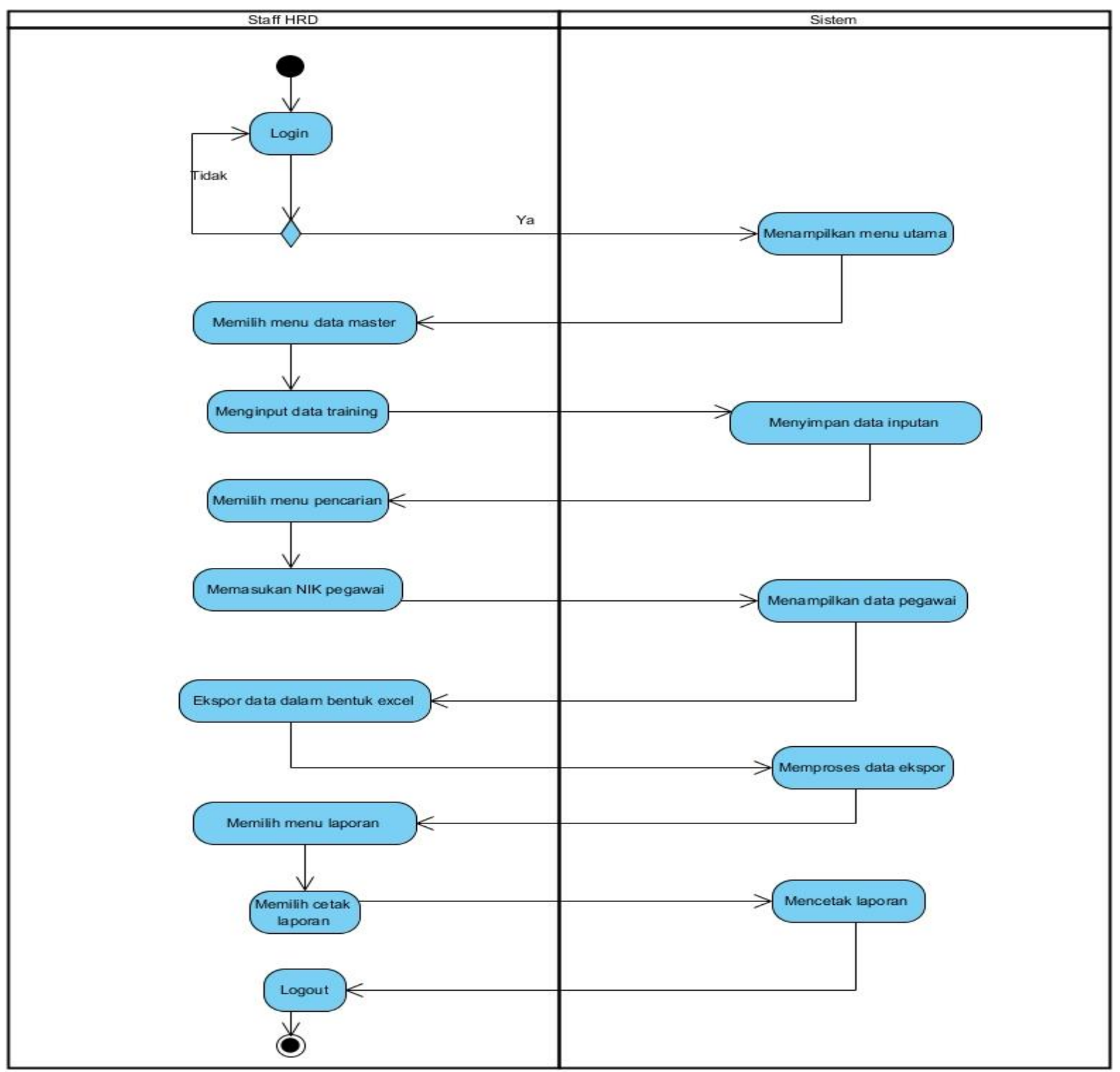

Gambar 3. Activity Diagram Rekam BT Training Centre

Pada Activity Diagram diatas dapat dideskripsikan sebagai berikut:

1. Sistem menampilkan login dan user memasukan username dan password jika benar maka akan diarahkan ke menu utama, jika salah maka akan kembali ke tampilan login.

2. User memilih menu data masater dan menginput data training serta menyimpan data

3. User memilih menu pencarian lalu memasukan NIK karyawan untuk menampilkan data pegawai dan sistem bisa untuk mengekspor data dalam bentuk Excel

4. User memilih menu laporan untuk memilih cetak laporan dan sistem memprosesnya dalam bentuk PDF.

5. User logout 


\section{Class Diagram}

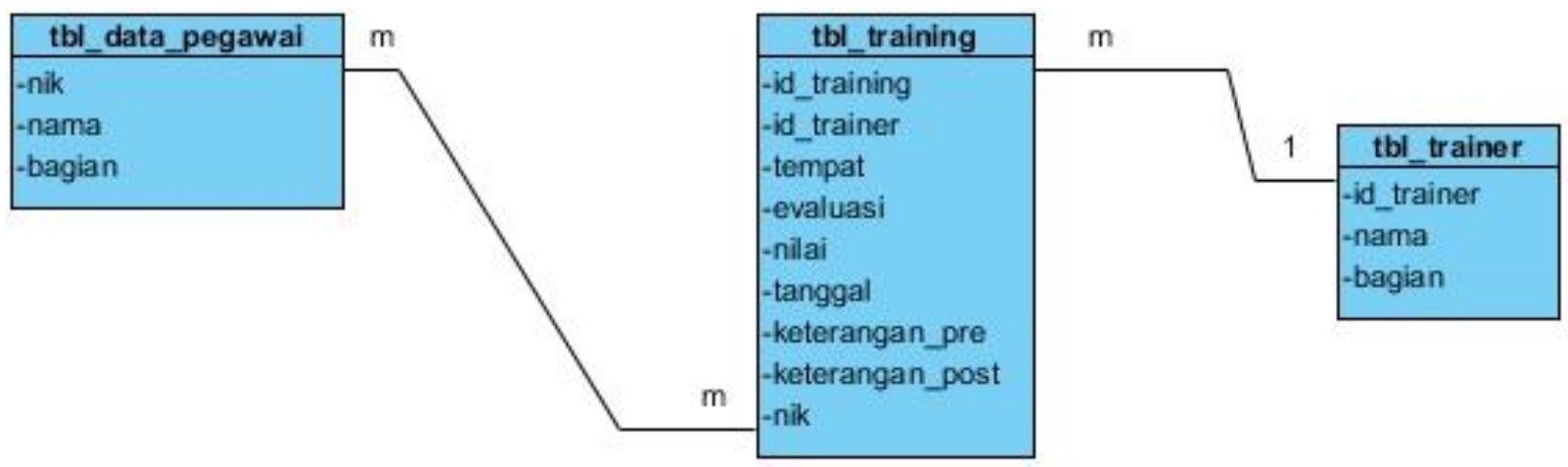

\section{Gambar 4. Class Diagram Rekam BT Training Centre}

Pada Class Diagram diatas dapat dideskripsikan sebagai berikut:

1.Class/table data pegawai memiliki relasi dengan training karena data dari sebuah training yang dilakukan diperlukan data pegawai yang mengikuti training.

2. Class/table training memiliki relasi dengan trainer karena data dari training yang dilakukan memerlukan data trainer yang melakukan training.

\section{TAMPILAN RANCANGAN SISTEM}

Dari hasil penjabaran diatas maka dapat dibuatkan sebuah sistem BT Training Centre, untuk memberikan penjelasan terhadap sistem yang dikembangkan, berikut penjelasannya:

1. Tampilan Awal Aplikasi

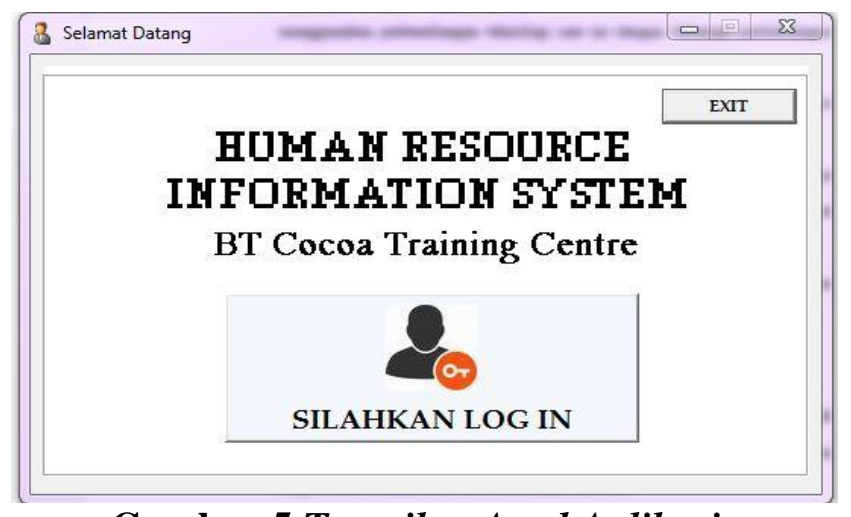

Gambar 5.Tampilan Awal Aplikasi

Didalam tampilan awal ini memperlihatkan tombol Login dan Exit yang berfungsi untuk masuk ke tampilan login username dan password dan keluar aplikasi. 
2. Menu Login

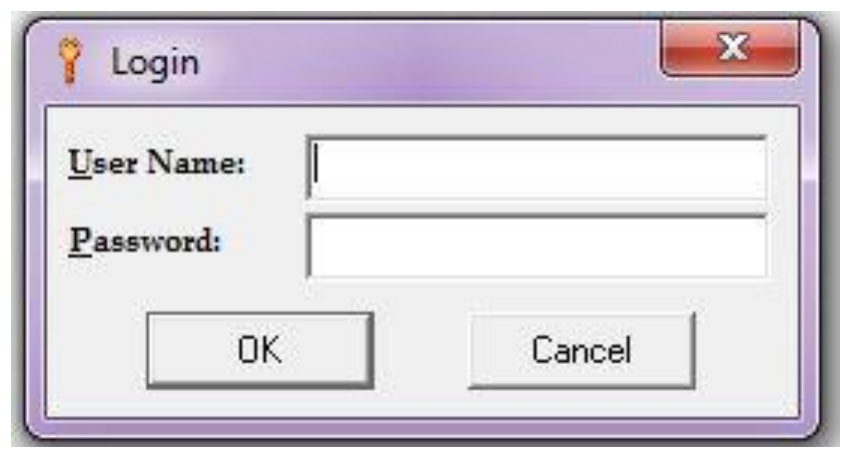

\section{Gambar 6. Menu Login}

Berisikan username dan password yang telah disetel sebelumnya di dalam database.

3. Beranda Aplikasi

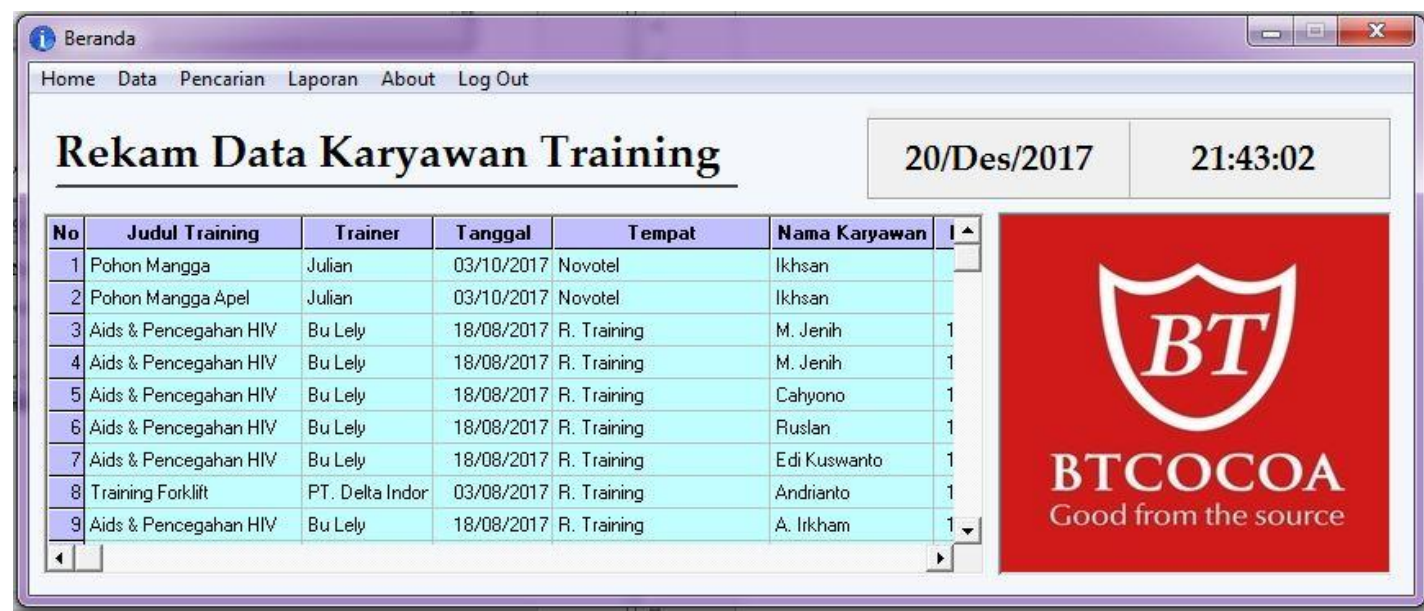

\section{Gambar 7. Beranda Aplikasi}

Berisikan informasi karyawan yang telah melakukan training serta memperlihatkan logo perusahaan, tanggal, waktu, beserta menu aplikasi.

4. Form Input Data

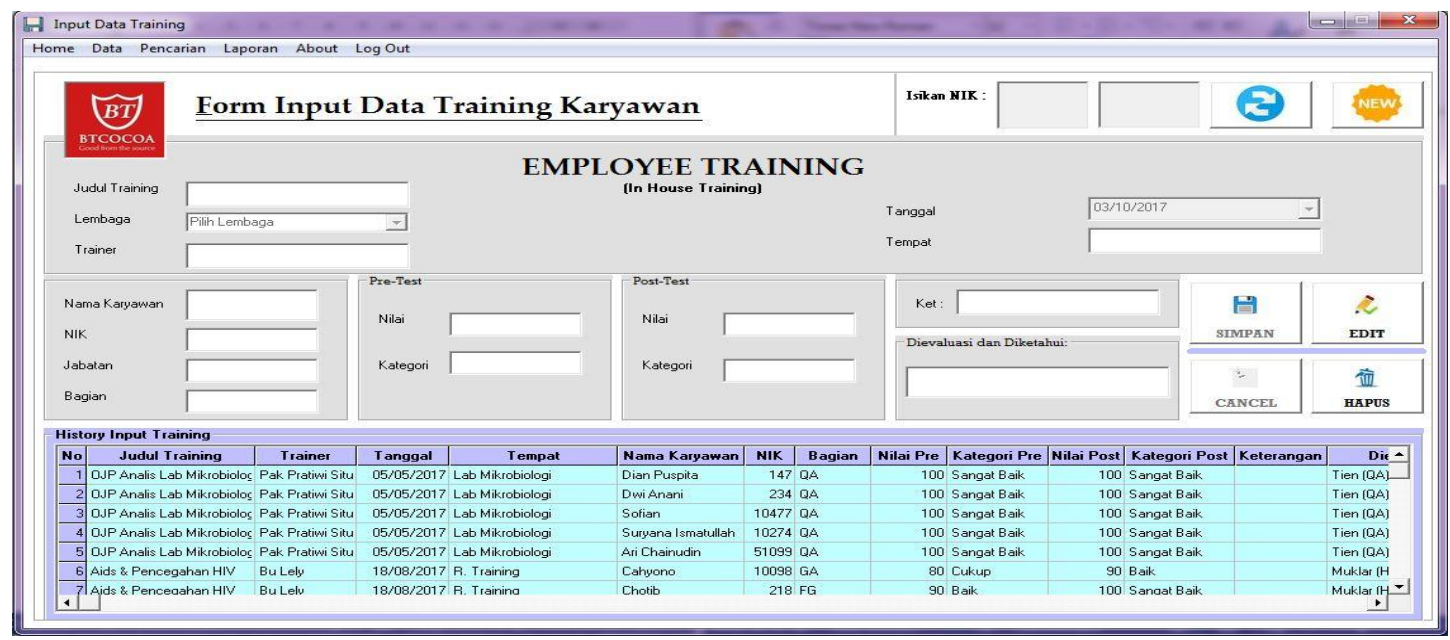

Gambar 8.Form Input Data 
Berisikan menu penginputan data karyawan beserta tombol edit, delete, cari, cancel dan juga logo perusahaan dan menu navigasi aplikasi.

5. Pencarian Data

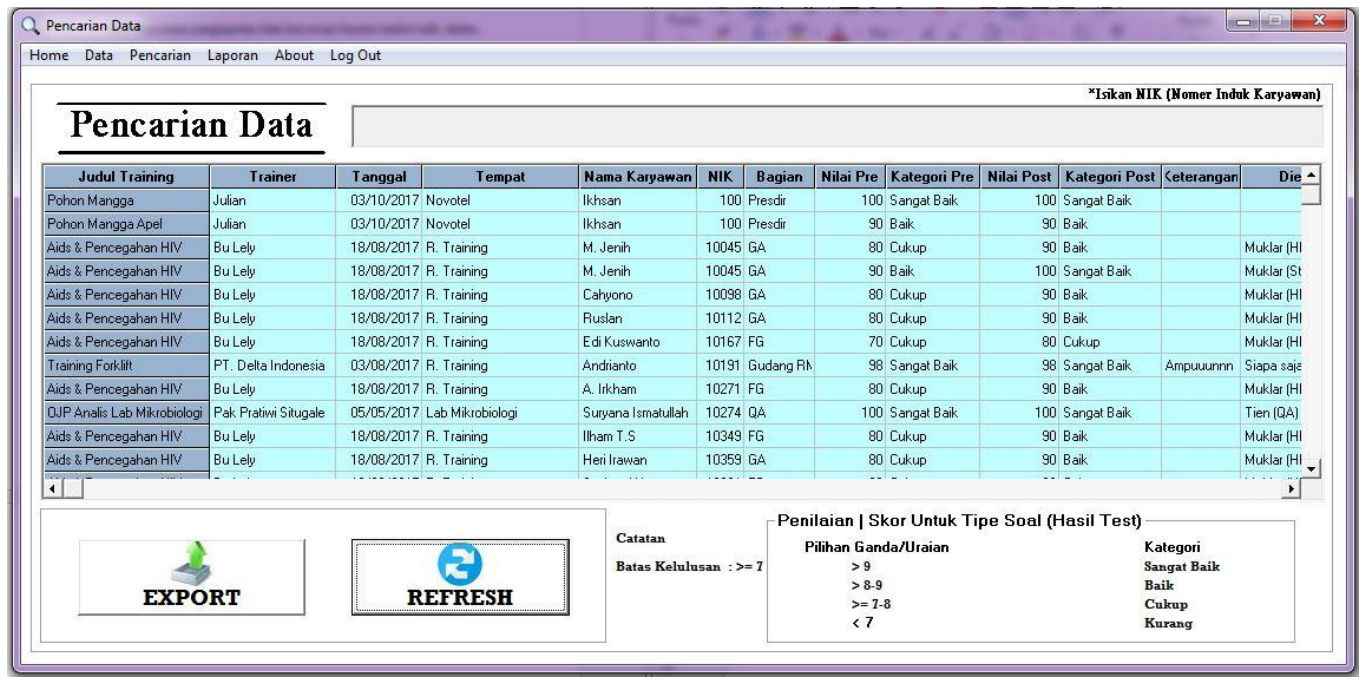

Gambar 9. Pencarian Data

Berisikan menu untuk mencari data karyawan yang sudah melakukan training sebelumnya dengan mengetikan NIK terlebih dahulu.

6. Form Laporan

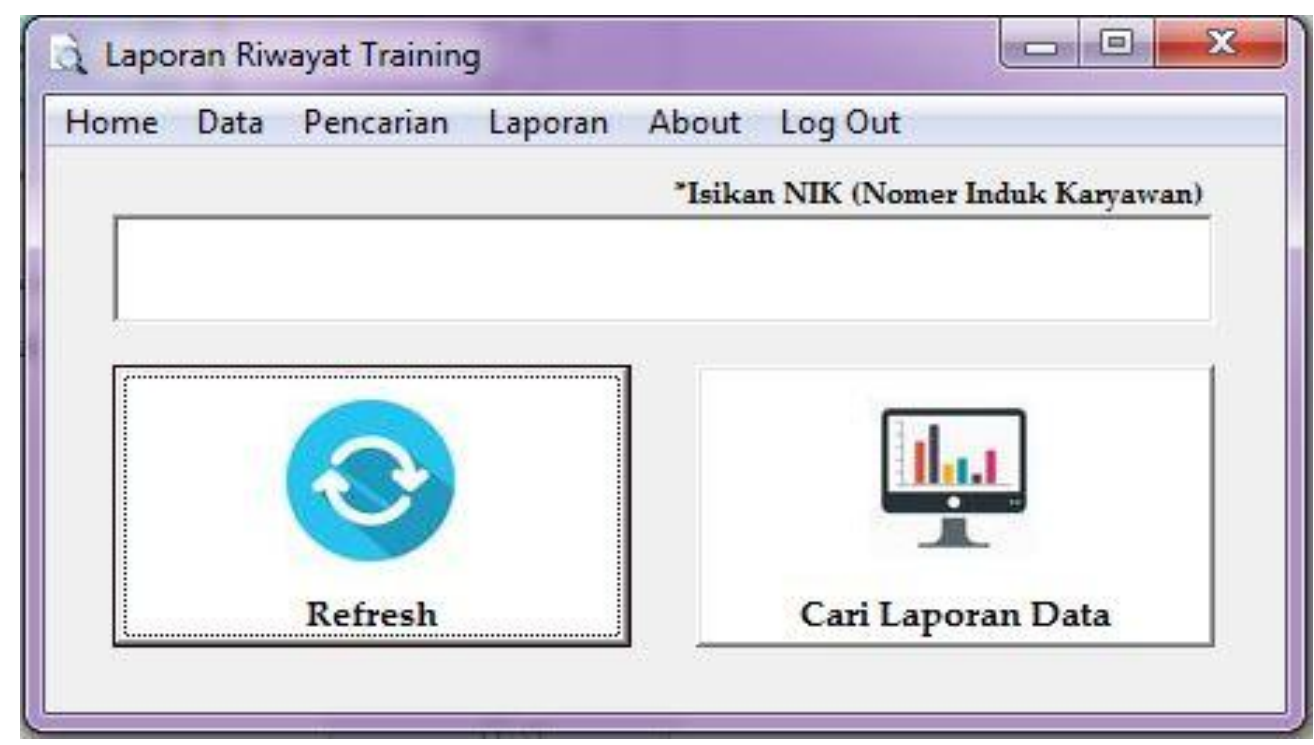

Gambar 10.Form Laporan

Berisikan tombol untuk melihat laporan karyawan yang telah melakukan training dengan mengetikan NIK terlebih dahulu. 


\section{Hasil Laporan}

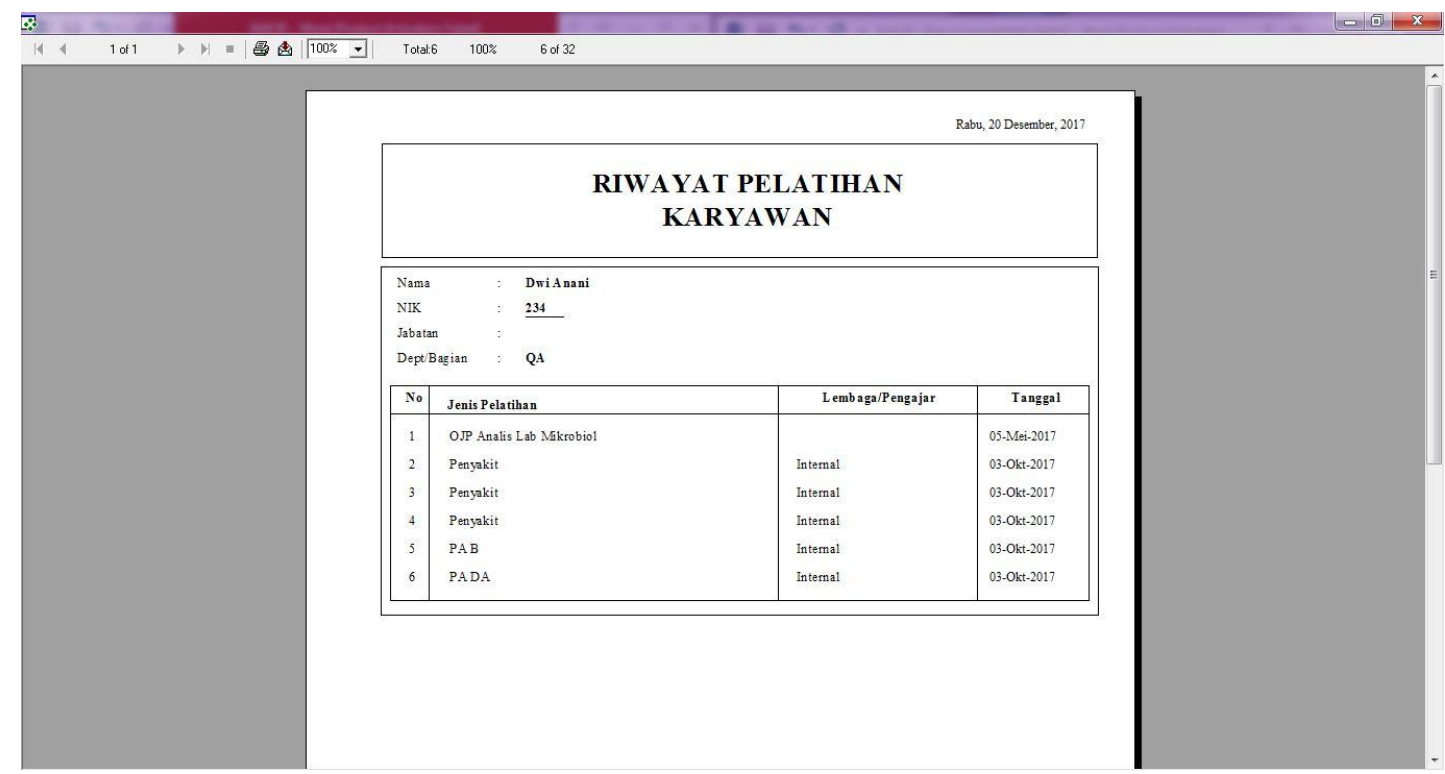

Gambar 11. Form Laporan

Berisikan tentang hasil laporan training karyawan yang diseleksi dengan mengetikan terlebih dahulu NIK dan bisa diekspor ke format Excel dan PDF.

\section{KESIMPULAN}

Berdasarkan hasil dari analisa dari penelitian yang telah dilakukan mengenai Sistem Rekam BT Training pada PT. Bumitangerang Mesindotama, maka pada penelitian ini dapat disimpulkan sebagai berikut :

1. Sebagian besar sistem yang terdapat pada departemen HRD sudah terkomputerisasi namun masih terkendala seperti masih banyaknya dokumen karyawan yang sulit terekam dikarenakan hilangnya atau belum direkam secara maksimal, cara mengatasinya harus dibangunnya sebuah sistem yang dapat mempermudah dalam hal penginputan data training karyawan agar data tidak mudah hilang dan mudah untuk dicari.

2. Pada departement HRD sebenarnya sudah melakukan penginputan data yang terkomputerisasi, hanya saja masih terlihat rumit dengan memisahkan data satu dengan data yang lainnya yang berujung ketidakmaksimalan pencarian data.

3. Belum terkesan maksimal dalam pengumpulan data karyawan yang telah melakukan training, yang berimbas pada pemilihan jenjang karir karyawan.

4. Diperlukannya sebuah aplikasi HRIS yang bertumpu pada rekam data training karyawan agar semua data karyawan yang telah mengikuti dapat tersimpan rapi, jika suatu saat diperlukan maka data akan mudah dicari sebagai penunjang data jenjang karir.

Dengan dibangunnya sistem baru yang dikembangkan akan mempermudah staff HRD dalam melakukan penginputan data karyawan yang telah melakukan pelatihan, serta memudahkan dalam pencarian data yang juga bisa diekspor kedalam bentuk Excel maupun PDF, serta mempermudah di dalam penggunaannya. 


\section{SARAN}

Dengan melihat kesimpulan diatas, penulis dapat memberikan saran-saran sesuai dengan apa yang terjadi dilapangan serta dapat membantu di dalam pengembangan sistem :

1. Sistem seharusnya dikembangkan menjadi suatu hal yang user friendly agar pengguna dapat memanfaatkan sistem menjadi hal yang mudah untuk digunakan.

2. Sistem harus dikembangkan lagi tidak hanya mencaut didalam hal pelatihan saja melainkan data lainnya agar dapat menampung semua data yang menyangkut hal karyawan di suatu perusahaan.

3. Selalu mengedepankan privasi data semua karyawan.

4. Dalam melakukan pelatihan perusahaan disarankan untuk meningkalkan sistem manual dan beralih ke sistem yang terkomputerisasi namun mengedepankan keamanan data perusahaan.

\section{DAFTAR PUSTAKA}

[1] Agusta, Leonardo dan Susanto, Eddy Madiono. 2013. Pengaruh Pelatihan dan Motivasi Kerja terhadap Kinerja Karyawan CV Haragon Surabaya. Jurnal dari universitas Kristen Petra Surabaya, Vol.1 No.3. [online]. Tersedia di http://repository.petra.ac.id. [02 November 2017]

[2] Al-Bahra Bin Ladjamudin. 2013. Analisis dan Desain Sistem Informasi. Graha Ilmu: Yogyakarta.

[3] Hartono, Bambang. 2013. Sistem Informasi Manajemen Berbasis Komputer. Jakarta: Rineka Cipta.

[4] KamusBisnis, "Kamus Bisnis dan Manajemen", http://kamusbisnis.com/arti/rekam-jejak/ (diakses 12 Maret 2018)

[5] Sedarmayanti, 2013. Manajemen Sumber Daya Manusia, Bandung: Refuka Aditama.

[6] Susanto, Azhar. 2013. Sistem Informasi Akuntansi. Bandung: Lingga Jaya.

[7] Ainnur Rofiq, Sholiq, dan Feby Artwodini Muqtadiroh. 2013. Rancang Bangun Aplikasi Sistem Informasi Manajemen Pelatihan (SIMPEL) pada Lembaga Pelatihan XYZ. Jurnal dari Institut Teknologi Sepuluh Nopember, Vol 2, No. 1.

[8] Sayeti, Imanaji Hari. 2013. Anallis Pengembangan Sistem Aplikasi E-Training Karyawan Berbasis WEB Pada PT. Mutiara Solusindo.

[9] Tri Retnowati, Agung. 2017. APLIKASI PEMBEKALAN KARYAWAN BARU DI YOMART MENGGUNAKAN TRAINING JARAK JAUH. Jurnal Computech \& Bisnis, Vol. 11, No. 1, Juni 2017, ISSN 2442.4943.

[10] Octorasari, Dian ,Weda Adistianaya Dewa. 2016. APLIKASI PELATIHAN INTERAKTIF PADA PT. KSI (PT. KOSMETIKATAMA SUPER INDAH - INEZ KOSMETIK). Jurnal DINAMIKA DOTCOM, Vol. 7, No. 2, Tahun 2016, ISSN 2086.2652. 